\title{
Association of objectively measured physical activity and sedentary time with health-related quality of life in women with fibromyalgia.
}

\author{
Blanca Gavilán Carrera
}

Tutor: Víctor Segura Jiménez. Departamento de Educación Física y Deportiva, Facultad de Ciencias del Deporte, Universidad de Granada Cotutor: Pedro Femia Marzo. Departamento de Bioestadística. Facultad de Medicina. Universidad de Granada

Máster de Investigación en Actividad Física y Deporte Trabajo Fin de Máster

Departamento de Educación Física y Deportiva

Facultad de Ciencias del Deporte

Universidad de Granada

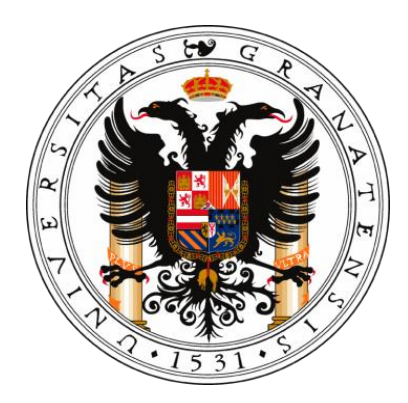




\title{
TRABAJO FIN DE MÁSTER
}

\author{
Alumna: \\ BLANCA GAVILÁN CARRERA
}

Firmado:

Tutor:

Cotutor:

VICTOR SEGURA JIMÉNEZ

Firmado:

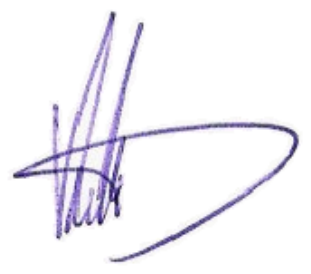

Firmado:

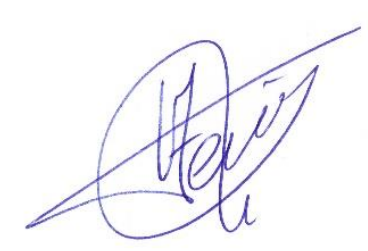




\section{Content}

ABSTRACT

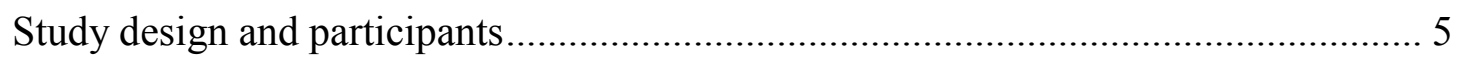

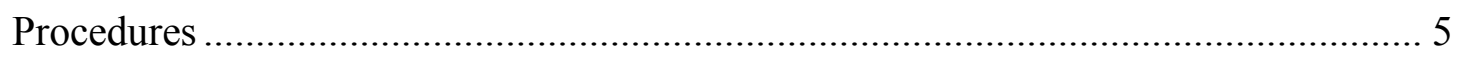

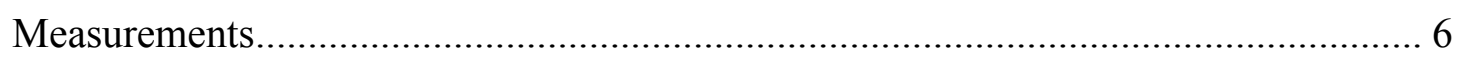

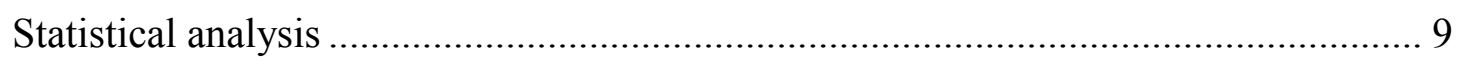

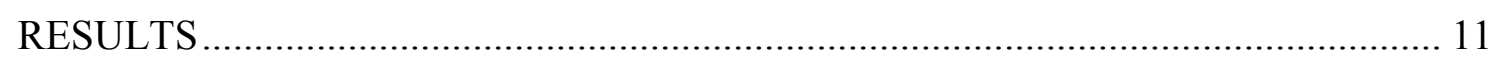

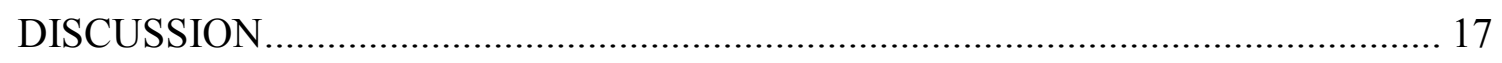

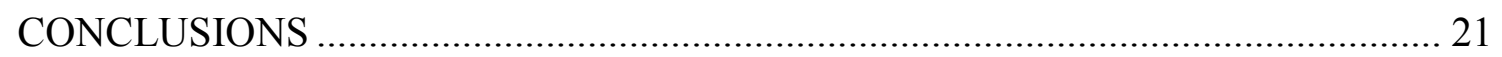

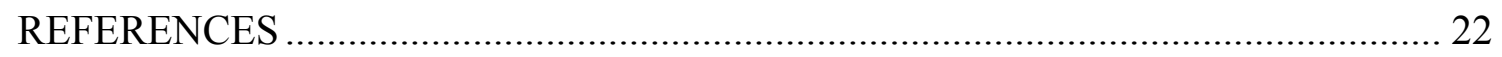

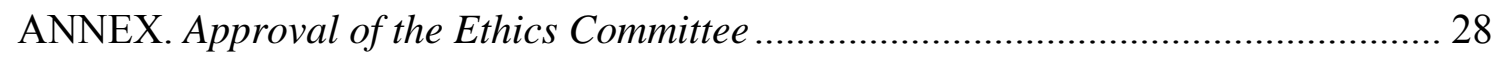




\section{ABSTRACT}

Objective: To examine the independent association of objectively measured physical activity (PA) intensity levels and sedentary time with health-related quality of life (HRQoL) in fibromyalgia women and whether patients meeting the current PA guidelines present better HRQoL than patients not meeting the current PA guidelines.

Methods: The study comprised 407 women with fibromyalgia (51.4 \pm 7.6 years old). Objectively measured (accelerometry) PA intensity levels and sedentary time were calculated (min/day), as well as the proportion of women meeting the current PA recommendations $(\geq 150$ minutes/week of moderate-to-vigorous intensity in bouts $\geq 10$ minutes). HRQoL was assessed using the 36-item Short-Form Health Survey (SF-36).

Results: All PA intensity levels positively correlated with different HRQoL dimensions ( $\mathrm{r}_{\text {partial }}$ between 0.108 and 0.226 ; all, $p<0.05$ ). Vigorous PA was independently associated with physical function, bodily pain and social functioning (all, $p<0.05$ ). Sedentary time was independently associated with physical function, physical role, bodily pain, vitality, social functioning, and both the physical and mental components summary score (all, $p<0.05)$. Patients meeting the current PA recommendations presented better bodily pain $($ mean $(95 \%-C I)=24.2(21.3-27.2)$ vs $20.4(18.9-21.9), p=0.023)$ and social functioning $($ mean $(95 \%-C I)=48.7(43.9-44.8)$ vs. $42.3(39.8-44.8), p=0.024)$ than those who did not meet the current PA recommendations.

Conclusions: Greater vigorous PA and lower sedentary time are independently associated with better HRQoL in fibromyalgia women. Furthermore, meeting the current PA recommendations is significantly associated with better bodily pain and social functioning. These results highlight the importance of being physically active and avoid sedentary time in this population.

Key words: GT3X+; accelerometry; sedentary time; physical activity levels; fibromyalgia; health-related quality of life. 


\section{RESUMEN}

Objetivo: Estudiar la asociación independiente de los niveles de actividad física (AF) y el tiempo de sedentarismo objetivamente medidos con la calidad de vida relacionada con la salud (CdVRS) en mujeres con fibromialgia y comprobar si las pacientes que cumplen las recomendaciones de AF presentan una mejor CdVRS que aquellas que no las cumplen. Método: En el estudio participaron 407 mujeres con fibromialgia (51.4 \pm 7.6 años). Los niveles de AF y el tiempo de sedentarismo (minutos/día) se midieron con acelerometría y la proporción de mujeres que cumplían las recomendaciones de $\mathrm{AF} \quad(\geq 150$ minutos/semana de AF de intensidad moderada-vigorosa acumulados en periodos de al menos 10 minutos). La CdVRS se midió usando el cuestionario de salud SF-36 (36-item Short-Form Health Survey).

Resultados: Todos los niveles de actividad física se relacionaron con diferentes dimensiones de la CdVRS ( $\mathrm{r}_{\text {parcial }}$ entre 0.108 y 0.226 ; todo, $p<0.05$ ). La AF vigorosa se asoció independientemente con la función física, dolor corporal y función social (todo, $p<0.05)$. El tiempo de sedentarismo se asoció independientemente con la función física, el rol físico, el dolor corporal, la vitalidad, la función social, el componente físico y el componente mental (todo, $p<0.05$ ). Las pacientes que cumplen las recomendaciones presentaron una puntuación significativamente mayor en las dimensiones dolor (media $(95 \%-\mathrm{IC})=24.2(21.3-27.2)$ vs $20.4(18.9-21.9), p=0.023)$ y función social (media $(95 \%$ IC) $=48.7(43.9-44.8)$ vs. $42.3(39.8-44.8), p=0.024)$.

Conclusiones: Mayor AF vigorosa y menor tiempo de sedentarismo se asocian independientemente con mejor CdVRS en mujeres con fibromialgia. Además, cumplir las recomendaciones de AF se asocia significativamente con mejor dolor y función social. Estos resultados confirman la importancia de mantenerse físicamente activo y evitar las conductas sedentarias en esta población.

Palabras clave: GT3X+; acelerometría; tiempo de sedentarismo; niveles de actividad física; fibromialgia; calidad de vida relacionada con la salud. 


\section{INTRODUCTION}

Fibromyalgia is a chronic condition with persistent and widespread pain as key symptom but the inclusion of other symptoms such as fatigue, non-restorative sleep, cognitive difficulties (1), muscle stiffness, impaired physical capacity (2) anxiety and depression (3). The large symptomatology associated with fibromyalgia limits individuals' functioning and, consequently, patients usually report a considerable negative impact in their health related quality of life (HRQoL) (4). The term HRQoL represents the individuals' perception of physical, mental and social health status (5) and there is evidence that it is a predictor of mortality $(6,7)$ and hospitalization $(6,8)$. When it comes to chronic conditions with no cure, treatment goals should then focus on the improvement of HRQoL along with symptomatology management (9-11).

Physical exercise has shown to be an alternative to pharmacology treatments in fibromyalgia $(10,12,13)$. Programs introducing exercise may have positive effects on HRQoL $(13,14)$ physical function, pain (15) and global symptomatology in this population $(16,17)$. However, there is little evidence about the relationship between daily levels of physical activity (PA) and HRQoL in fibromyalgia patients, so far. Previous studies have observed a positive association between PA and HRQoL in diverse populations such as older adults $(18,19)$, adults $(20,21)$, individuals with arthritis $(22)$, middle aged (23) and elderly women $(24,25)$ or multiple sclerosis $(26)$. This tendency has been confirmed in fibromyalgia patients: those who remain more physically active report better physical HRQoL $(9,27)$. Nonetheless, fear of pain and worsening of symptoms lead patients to avoid physical activities (28) and only $20 \%$ of them seem to meet the PA recommendations for health benefits $(29,30)$. Additionally, it is unknown whether diverse PA intensity levels are independently associated with HRQoL, and which of these PA intensity levels shows the strongest associations. 
Fibromyalgia patients also present more sedentary habits compared to healthy individuals spending, on average, $48 \%$ of their waking time in sedentary behaviour (30) (which include activities that involve sitting or reclining and only low levels of energy expenditure (31)). Sedentary behaviour has recently grown as a focus of study and has shown to have negative consequences on health independent of those related to insufficient exercise $(32,33)$. Furthermore, evidence suggests that sedentary time is linked to detriments in HRQoL in adults, older adults (19), early schizophrenia (34) and healthy women (35). However, little is known about this relationship in fibromyalgia.

Therefore, the aims of the current study were to test: 1) the association of diverse objectively measured PA intensity levels and sedentary time with HRQoL in women with fibromyalgia; 2) which of the aforementioned variables are independently associated with HRQoL; 3) whether patients meeting the current PA guidelines present better HRQoL compared to those not meeting the PA guidelines. 


\section{METHODS}

\section{Study design and participants}

A province proportional recruitment of fibromyalgia patients from Southern Spain (Andalusia) was planned, as described elsewhere (36). Briefly, patients were contacted through fibromyalgia associations, email and social media (radio, Internet, newspaper). After providing detailed information about the aims and study procedures, we obtained written informed consent from all study participants. A total of 646 fibromyalgia patients agreed to participate in the study. Inclusion criteria for the current study were: (i) to be previously diagnosed by a rheumatologist and meet the official 1990 American College of Rheumatology (ACR) fibromyalgia criteria (widespread pain for more than 3 months, and pain with $4 \mathrm{~kg} / \mathrm{cm}^{2}$ of pressure reported for 11 or more of 18 tender points) (37) (ii) have neither acute or terminal illness nor severe cognitive impairment (Mini Mental State Examination $[\mathrm{MMSE}](38)$ score $<10)$ and (iii) be $\leq 65$ years. Thirty-nine women with fibromyalgia were not previously diagnosed, 99 did not meet the 1990 ACR criteria, 1 had severe cognitive impairment and 14 did not meet the age criteria. Due to the small sample $(n=21)$, fibromyalgia men were not included in the current study. The Ethics Committee of the Hospital Virgen de las Nieves", Granada (Spain) approved the study (included as an Annex).

\section{Procedures}

On day one, the MMSE was interviewed and participants filled out self-reported sociodemographic data and drug consumption questionnaires. Tender points, anthropometry and body composition were also assessed. The 36-item Short-Form Health Survey (SF-36) and the Revised Fibromyalgia Impact Questionnaire (FIQR) (39) 
were given to patients to be completed at home. Two days later, patients returned to the laboratory and the questionnaires were collected. Then, patients received the accelerometer and were instructed on how to fill out the sleep diary. Participants returned the accelerometers to the research team 9 days later.

\section{Measurements}

\section{Health related quality of life (HRQoL)}

HRQoL was assessed using the SF-36, which has been validated for Spanish populations (40). This questionnaire is composed of 36 items, which include questions about both physical and mental health. It assesses 8 dimensions (physical functioning, role-physical, bodily pain, general health, social functioning, role-emotional, mental health, vitality) and two component summary scores (physical and mental health). Each dimension score is standardized (range 0-100), where 0 indicates the worst possible health status and 100 the best possible.

\section{Sedentary time and physical activity levels}

Data was collected using triaxial accelerometer GT3X+ (Actigraph, Pensacola, Florida, USA) using the default mode filter option at a rate of $30 \mathrm{~Hz}$ and stored at an epoch length of 60 second (41). Participants wore the device on the hip near to the center of gravity, underneath clothing and secured with an elastic belt. The accelerometer was carried over the whole day (24 h) except during water-based activities such as bathing or swimming.

PA was recorded up to 9 days, starting from the day the participants received the accelerometers until the day that they were instructed to return the device. PA data from the first recorded day (to avoid reactivity) and last day (return back device) were 
excluded. A total of 7 continuous days with a minimum of 10 valid hours was required to be included in the study analysis. Bouts of 90 continuous minutes (30 minutes small window length and 2 minutes skip tolerance) of 0 counts were considered as non-wear periods and excluded from the analysis (42). Data download, reduction, cleaning and analyses were performed using the manufacturer software (Actilife ${ }^{\mathrm{TM}} \mathrm{v} \cdot 6.11 .7$ desktop).

Accelerometer wearing time was calculated by subtracting the sleeping time (obtained from the sleep diary where patients wrote time they went to bed and time they woke up) from each day. Sedentary time was estimated as the amount of time accumulated below 200 counts per minute (cpm) during periods of wear time (43). PA intensity levels (light, moderate and vigorous) were calculated based upon recommended PA vector magnitude cut points (41-43): 200-2689, 2690-6166 and $\geq 6167 \mathrm{cpm}$, respectively. All values were expressed in min/day. We also summed moderate and vigorous PA to obtain a moderate-to-vigorous PA (MVPA) intensity level, and calculated the proportion of women meeting the PA recommendations for adults aged 18-64 years ( $\geq 150$ minutes/week of MVPA in at least 10 minutes at a time) (29).

\section{Cognitive function}

The Mini Mental State Examination (MMSE) (38) was used to evaluate cognitive capacity and severity of dementia. It is a brief test which assesses 5 areas (orientation, immediate memory, attention/concentration, delayed recall and language) and it was used for exclusion criteria purpose only.

\section{Tenderness}

Eighteen tender points were assessed according to the 1990 ACR fibromyalgia criteria (37) using a standard pressure algometer (FPK 20; Wagner Instruments, 
Greenwich, CT, USA). The mean pressure of two measurements at each tender point was used and scored as positive tender point if the patient noted pain at pressure $\leq 4 \mathrm{~kg} / \mathrm{cm}^{2}$. The total count of positive tender points was recorded for each participant.

\section{Sociodemographic data}

We collected socio-demographic data by using a self-reported questionnaire including age, marital status (married/ not married), educational level (university/nonuniversity) and occupational status (working/housewife/not working)

\section{Fibromyalgia severity}

Fibromyalgia severity was assessed with the Spanish version of the FIQR (39). It is composed of ten subscales: physical impairment, overall well-being, work missed, and a seven items (subscales) of a visual analog scale marked in 1-cm increments on which the patient rates the work difficulty, pain, fatigue, morning tiredness, stiffness, anxiety, and depression. The FIQR score uses a 'last 7 days' time frame and ranges from 0 to 100. A higher value indicates a higher impact of fibromyalgia.

\section{Anthropometry and body composition}

A portable eight-polar tactile electrode impedanciometer (InBody R20, Biospace, Seoul, Korea) was used to measured weight $(\mathrm{kg})$ and total body fat $(\%)$. The validity and reliability of this instrument has been reported elsewhere $(44,45)$. As the manufacturer recommends, we requested participants not to have a shower, not to practice intense PA and not to ingest large amounts of fluid and/or food in the 2 hours before the measurement. Patients were also asked not to wear either clothing (except underwear) or metal objects during the measurement. Height $(\mathrm{cm})$ was measured using a stadiometer 
(Seca 22, Hamburg, Germany). Body mass index (BMI) was calculated as weight (kg) divided by height (m) squared.

\section{Drug consumption}

Patients reported the consumption of antidepressants and analgesics (yes or no) during the previous 2 weeks.

\section{Statistical analysis}

Descriptive statistics were used to examine the sociodemographic and clinical characteristics of the sample. Pearson's partial correlation was used to study the association of the different physical activity levels (light PA, moderate PA, vigorous PA, MVPA) and sedentary time with HRQoL. Age, marital status, educational level, current occupational status, body fat percentage, drug consumption (both analgesics and antidepressants) and total accelerometry-wear time were entered as covariates. Then, to explore the independent association of PA intensity levels and HRQoL, linear regression analyses were performed. All the dimensions of HRQoL (physical functioning, rolephysical, bodily pain, general health, social functioning, role-emotional, mental health, vitality) and the two component summary scores (physical and mental health) were entered as dependent variables in separate models. All the PA intensity levels, sedentary time, and all the covariates (sociodemographic variables, drugs consumption, body fat percentage), were entered simultaneously using a stepwise procedure. This procedure introduces the variables step by step into the model (if $p<0.05$ ) according to the strength of the association with the outcome. Accelerometer wear time was introduced with the 'enter' procedure to control all the analyses for its effect. 
Differences in HRQoL of patients meeting vs. not meeting the current PA recommendation were calculated with Multivariate analysis of covariance (MANCOVA). The 8 dimensions and the 2 component summary scores of HRQoL were entered as dependent variables and sociodemographic variables, body fat percentage, drugs consumption and accelerometry wearing time were entered as covariates.

Normality was assumed due to the large sample size and homoscedasticity assumption of HRQoL (assessed with Levene's test) was reasonably met between patients meeting and not meeting recommendations of PA. All analyses were performed using the Statistical Package for Social Sciences, version 20.0 (SPSS Statistics for Windows, IBM, Armonk, NY, USA), and the level of significance was set at $p<0.05$. 


\section{RESULTS}

Seventeen participants did not finally wear the accelerometer and data from 3 participants were lost due to accelerometer malfunction. Seventeen participants did not meet the accelerometer criteria and 28 did not returned completed questionnaires. The final sample size comprised 407 women with fibromyalgia. Patients' sociodemographic characteristics are shown in Table 1 and clinical characteristics are shown in Table 2.

Table 1. Socio-demographic characteristics of the study group $(n=407)$.

\begin{tabular}{lll}
\hline Characteristic & $\mathrm{n}$ & $(\%)$ \\
\hline Age, years; mean (SD) & 51.4 & $(7.6)$ \\
Marital status & & \\
$\quad$ Married & 311 & $(76.4)$ \\
$\quad$ Not married & 96 & $(23.6)$ \\
Educational level & & \\
$\quad$ Non university & 349 & $(85.7)$ \\
$\quad$ University & 58 & $(14.3)$ \\
Current occupational Status & & \\
$\quad$ Working & 107 & $(26.3)$ \\
$\quad$ Housewife & 128 & $(31.4)$ \\
$\quad$ Not working & 172 & $(42.3)$ \\
\hline
\end{tabular}

SD: standard deviation.

Pearson's partial correlations of physical activity intensity levels and sedentary time with HRQoL are presented in Table 3. Light PA was significantly associated with physical function, bodily pain, vitality and social functioning ( $\mathrm{r}_{\text {partial }}$ between 0.108 and 0.196, all $p<0.05)$. Moderate PA was significantly associated with physical function, physical role, vitality, social functioning and physical component ( $\mathrm{r}_{\text {partial }}$ between 0.103 and 0.220 , all $p<0.05$ ). Vigorous PA was significantly associated with physical function, bodily pain, social functioning and emotional role ( $\mathrm{r}_{\text {partial }}$ betweeen 0.101 and 0.137 , all $p<0.05)$. MVPA was significantly associated with physical function, physical role, vitality, social functioning and the physical component $\left(\mathrm{r}_{\text {partial }}\right.$ between 0.107 and 0.226 , all $p<0.05)$. Sedentary time was inversely associated with all the dimensions of HRQoL ( $\mathrm{r}_{\text {partial }}$ between -0.241 and -0.108 , all $\left.p<0.05\right)$, except for general health, emotional role and mental health. 
Table 2. Clinical characteristics of the women with fibromyalgia $(n=407)$.

\begin{tabular}{|c|c|c|}
\hline Variables & Mean & S.D. \\
\hline FIQR Total score (0-100) & 64.4 & 16.8 \\
\hline Total tender points (11-18) & 16.7 & 2.0 \\
\hline Algometer Score (18-144) & 43.2 & 13.4 \\
\hline $\mathrm{BMI}\left(\mathrm{Kg} / \mathrm{m}^{2}\right)$ & 28.4 & 5.4 \\
\hline Body fat (\%) & 40.1 & 7.6 \\
\hline \multicolumn{3}{|l|}{ Drugs consumption } \\
\hline Analgesics (yes) (n, \%) & 367 & 90.2 \\
\hline Antidepressants (yes) (n, \%) & 232 & 57.0 \\
\hline \multicolumn{3}{|c|}{ Health Related Quality of Life, SF-36 (0-100) } \\
\hline Physical function & 39.2 & 18.9 \\
\hline Physical role & 33.2 & 21.2 \\
\hline Bodily pain & 21.2 & 14.7 \\
\hline General health & 28.5 & 15.3 \\
\hline Vitality & 22.3 & 17.7 \\
\hline Social functioning & 43.7 & 24.7 \\
\hline Emotional role & 56.9 & 27.9 \\
\hline Mental health & 46.2 & 19.7 \\
\hline Physical Component & 29.5 & 6.9 \\
\hline Mental Component & 36.0 & 11.6 \\
\hline \multicolumn{3}{|l|}{ PA and sedentary time (min/day) } \\
\hline Accelerometer-wear time & 923.0 & 78.9 \\
\hline Sedentary Time & 460.1 & 104.1 \\
\hline Light PA & 418.6 & 91.8 \\
\hline Moderate PA & 43.9 & 29.5 \\
\hline Vigorous PA & 0.4 & 2.0 \\
\hline MVPA & 44.3 & 30.1 \\
\hline
\end{tabular}

BMI: Body Mass Index: FIQR: Revised Fibromyalgia Impact Questionnaire; MVPA: Moderate-tovigorous physical activity; PA: physical activity; SF-36: 36-item Short-Form Health Survey.

Table 3. Partial correlations of physical activity intensity levels and sedentary time with health-related quality of life $(n=407)$.

\begin{tabular}{llllll}
\hline \multicolumn{1}{c}{ Variables } & Light PA & $\begin{array}{c}\text { Moderate } \\
\text { PA }\end{array}$ & $\begin{array}{c}\text { Vigorous } \\
\text { PA }\end{array}$ & \multicolumn{1}{c}{ MVPA } & $\begin{array}{c}\text { Sedentary } \\
\text { Time }\end{array}$ \\
\hline Physical function & $0.108^{*}$ & $0.113^{*}$ & $0.122 *$ & $0.119^{*}$ & $-0.132 * *$ \\
Physical role & 0.077 & $0.127^{*}$ & 0.050 & $0.128^{* *}$ & $-0.108^{*}$ \\
Bodily pain & $0.110^{*}$ & 0.082 & $0.126 * *$ & 0.089 & $-0.124 * *$ \\
General health & 0.021 & 0.021 & 0.060 & 0.024 & -0.026 \\
Vitality & $0.124 *$ & $0.126^{* *}$ & 0.077 & $0.129 *$ & $-0.149 * *$ \\
Social functioning & $0.196 * *$ & $0.226^{* * *}$ & $0.137 * *$ & $0.226 * * *$ & $-0.241 * * *$ \\
Emotional role & 0.074 & 0.043 & $0.101 *$ & 0.049 & -0.080 \\
Mental health & 0.026 & 0.056 & 0.040 & 0.058 & -0.041 \\
Physical Component & 0.088 & $0.103 *$ & 0.082 & $0.107 *$ & $-0.110 *$ \\
Mental Component & 0.090 & 0.092 & 0.086 & 0.096 & $-0.109 *$ \\
\hline
\end{tabular}

MVPA: moderate-to-vigorous physical activity. PA: physical activity.

Analysis are controlled for age, body fat, current occupational status, educational level, marital status, accelerometer-wear time, consumption of analgesics and antidepressants.

${ }^{*} p<=0.05, * * p<=0.01, * * * p<=0.001$ 
The optimal regression model between PA intensity levels and sedentary time, and SF-36 dimensions as well as the 2 components summary score (physical and mental health) are shown in Table 4. Vigorous PA was the only PA intensity level independently associated with HRQoL [physical function $(b=1.100 ; p=0.016)$, bodily pain $(b=0.783$; $p=0.022)$ and social functioning $(\mathrm{b}=1.233 ; p=0.026)]$. Sedentary time was independently associated with physical function $(b=-0.029 ; p=0.002)$, physical role $(b=-0.029$; $p=0.006)$, bodily pain $(\mathrm{b}=-0.020 ; p=0.007)$, vitality $(\mathrm{b}=-0.030 ; p=0.001)$, social functioning $(\mathrm{b}=-0.064 ; p<0.001)$, and both the physical $(\mathrm{b}=-0.011 ; p=0.001)$ and mental components summary score $(b=-0.013 ; p=0.018)$. The standardized regression coefficients $(\beta)$ presented in Table 4 represent the change, in standard deviation units, in each dimension of HRQoL in response for a change of one standard deviation in each variable predictor. The percentage of variability explained by the models ranges from 4.8 $\%$ (adjusted $\mathrm{R}^{2}=0.048$ ) in the physical component to $21.7 \%$ (adjusted $\mathrm{R}^{2}=0.217$ ) in the social functioning dimension.

Figure 1 shows the differences in the dimensions of HRQoL in fibromyalgia women meeting vs. not meeting the current PA recommendations. MANCOVA analysis showed no significant differences between the two groups for global HRQoL (Hottelling$\left.\mathrm{T}^{2}: \mathrm{F}_{8,391}=0.027 ; p=0.239\right)$. In further analysis for each dimension, patients who met the current $\mathrm{PA}$ recommendations presented higher scores in bodily pain $(95 \%-\mathrm{CI}=(21.3-27.2)$ vs $(18.9-21.9), \mathrm{p}=0.023)$ and social functioning $(95 \%-\mathrm{CI}=(43.9-44.8)$ vs. $(39.8-44.8)$, $\mathrm{p}=0.024$ ) dimensions than those who did not meet the current PA recommendations. 
Table 4. Complete models of regression coefficients assessing the association of physical activity intensity levels and sedentary time with health-related quality of life ( $n=407)$.

\begin{tabular}{|c|c|c|c|c|c|}
\hline & $\beta$ & $\mathrm{b}$ & $(95 \% \mathrm{CI})$ & $\mathrm{p}$ & Adjusted $\mathrm{R}^{2}$ \\
\hline \multicolumn{6}{|l|}{ Physical function } \\
\hline Accelerometer-wear time & 0.150 & 0.036 & $(0.011,0.060)$ & 0.004 & \multirow{4}{*}{0.074} \\
\hline Medication for depression & -0.135 & -5.165 & $(-8.857,-1.472)$ & 0.006 & \\
\hline Vigorous PA & 0.117 & 1.100 & $(0.204,1.996)$ & 0.016 & \\
\hline Sedentary time & -0.162 & -0.029 & $(-0.048,-0.010)$ & 0.002 & \\
\hline \multicolumn{6}{|l|}{ Physical Role } \\
\hline Accelerometer wear time & 0.135 & 0.036 & $(0.009,0.064)$ & 0.009 & \multirow{5}{*}{0.134} \\
\hline Current ocupational status: & & & & & \\
\hline Working & 0.203 & 9.746 & $(5.247,14.244)$ & 0.000 & \\
\hline Medication for depression & -0.198 & -8.462 & $(-12.467,-4.458)$ & 0.000 & \\
\hline Sedentary time & -0.142 & -0.029 & $(-0.049,-0.008)$ & 0.006 & \\
\hline
\end{tabular}

Bodily pain

$\begin{array}{lcccccc}\text { Accelerometer wear time } & 0.058 & 0.011 & (-0.008, & 0.029) & 0.250 & \\ \text { Fat percentage } & -0.095 & -0.185 & (-0.363,-0.007) & 0.042 & 0.152 \\ \text { Medication for depression } & -0.303 & -8.994 & (11.748,-6.240) & 0.000 & \\ \text { Vigorous PA } & \mathbf{0 . 1 0 7} & \mathbf{0 . 7 8 3} & (\mathbf{0 . 1 1 5}, & \mathbf{1 . 4 5 1}) & \mathbf{0 . 0 2 2} & \\ \text { Sedentary time } & \mathbf{- 0 . 1 4 0} & \mathbf{- 0 . 0 2 0} & \mathbf{( - 0 . 0 3 4 ,}-\mathbf{- 0 . 0 0 5}) & \mathbf{0 . 0 0 7} & \end{array}$

General Health

Current ocupational status:

Not working

$-0.124 \quad-3.837$

$(-6.814, \quad-0.861) \quad 0.012$

0.086

Medication for depression

$-0.226-6.979$

$(-9.948,-4.009) \quad 0.000$

Medication for pain

$-0.098 \quad-5.043$

$(-9.897, \quad-0.190) \quad 0.042$

Vitality

$\begin{array}{lcccccc}\text { Accelerometer wear time } & 0.106 & 0.024 & (0.001,0.046) & 0.041 & \\ \text { Medication for depression } & -0.201 & -7.152 & (-10.600,-3.703) & 0.000 & 0.092 \\ \text { Medication for pain } & -0.094 & -5.577 & (-11.139,-0.014) & 0.049 & \\ \text { Sedentary time } & \mathbf{- 0 . 1 7 9} & \mathbf{- 0 . 0 3 0} & \mathbf{( - 0 . 0 4 8 ,}-\mathbf{- 0 . 0 1 3}) & \mathbf{0 . 0 0 1} & \end{array}$




\begin{tabular}{lcccccr}
\hline Social functioning & & & & & & \\
Accelerometer wear time & 0.170 & 0.053 & $(0.024,0.083)$ & 0.000 & \\
Age & 0.100 & 0.327 & $(0.041,0.612)$ & 0.025 & \\
Medication for depression & -0.283 & -14.064 & $(-18.535,-9.593)$ & 0.000 & 0.217 \\
Medication for pain & -0.091 & -7.563 & $(-14.794,-0.332)$ & 0.040 & \\
Vigorous PA & $\mathbf{0 . 1 0 0}$ & $\mathbf{1 . 2 3 3}$ & $\mathbf{( \mathbf { 0 . 1 4 9 } , \mathbf { 2 . 3 1 6 } )}$ & $\mathbf{0 . 0 2 6}$ & \\
Sedentary time & $\mathbf{- 0 . 2 6 9}$ & $\mathbf{- 0 . 0 6 4}$ & $\mathbf{( - 0 . 0 8 6 , - 0 . 0 4 1 )}$ & $\mathbf{0 . 0 0 0}$ &
\end{tabular}

Emotional role

$\begin{array}{llllll}\text { Accelerometer wear time } & 0.115 & 0.041 & (0.008, & 0.073) & 0.014\end{array}$

$\begin{array}{ll}\text { Current ocupational status: } & 0.161\end{array}$

$\begin{array}{llllll}\text { Working } & 0.127 & 8.039 & (2.273, & 13.804) & 0.006\end{array}$

$\begin{array}{llllll}\text { Medication for depression } & -0.343 & -19.323 & (-24.402, & -14.245) & 0.000\end{array}$

Mental health

$\begin{array}{lcccccc}\text { Accelerometer wear time } & 0.092 & 0.023 & (0.000, & 0.046) & 0.048 & 0.143 \\ \text { Medication for depression } & -0.362 & -14.391 & (-17.998, & -10.785) & 0.000 & \end{array}$

Physical component

$\begin{array}{llllll}\text { Accelerometer wear time } \quad 0.077 & 0.007 \quad(-0.002, & 0.016) & 0.149\end{array}$

Current ocupational status:

Working

0.143

2.241

$(0.708,3.774)$

0.004

Sedentary time

$-\mathbf{0 . 1 7 1}-\mathbf{- 0 . 0 1 1}$

$(-\mathbf{0 . 0 1 8},-\mathbf{- 0 . 0 0 4 )} \quad 0.001$

Mental component

$\begin{array}{lccccc}\text { Accelerometer wear time } & 0.150 & 0.022 & (0.008, & 0.036) & 0.002 \\ \text { Medication for depression } & -0.366 & -8.593 & (-10.735,-6.451) & 0.000 \\ \text { Medication for pain } & -0.093 & -3.651 & (-7.105, & -0.197) & 0.038 \\ \text { Sedentary time } & \mathbf{- 0 . 1 1 6} & \mathbf{- 0 . 0 1 3} & \mathbf{( - 0 . 0 2 4 ,} & \mathbf{- 0 . 0 0 2}) & \mathbf{0 . 0 1 8}\end{array}$

$\beta$, standardized regression coefficient; $b$, non-standardized regression coefficient; $C I$, confidence interval; PA, physical activity.

Stepwise regression using age, marital status, educational level, current occupational status, consumption of analgesics and antidepressants, body fat percentage, light PA, moderate PA, vigorous PA and sedentary time. Accelerometer-wear time was used as covariate (enter method) in all models. Physical activity levels and sedentary time are highlighted in bold. 


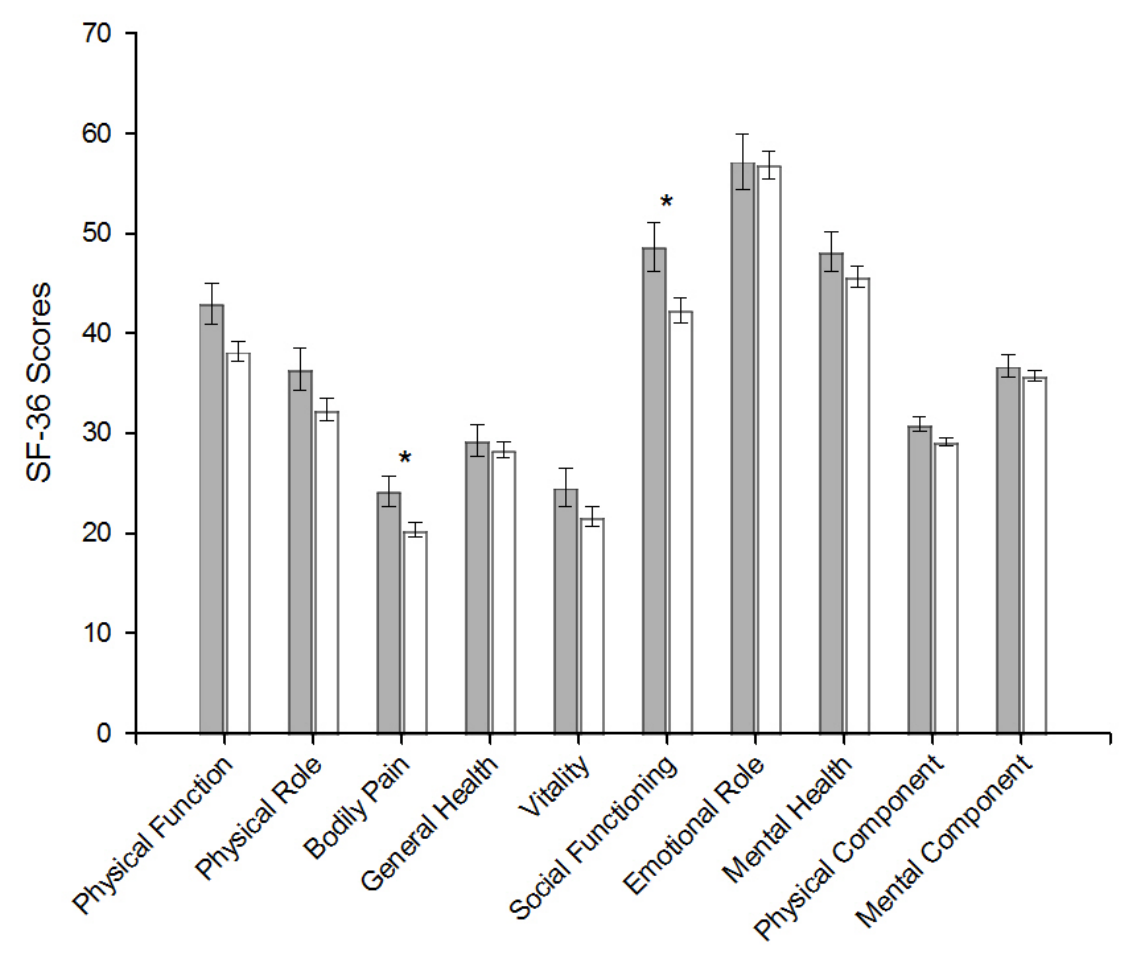

SF-36 Dimensions

(Hottelling- $\mathrm{T}^{2}: \mathrm{F}_{8,391}=0.027 ; p=0.239$ )

$* p<0.05$

Figure 1. Means (95\% confidence interval) of scores in the 36-item Short-Form Health Survey (SF-36) for each dimension in patients meeting and patients not meeting the current physical activity (PA) recommendations. Differences between groups were studied using multivariable analysis of covariance (MANCOVA) with sociodemographic variables (marital status, occupational status, educational level), body fat percentage, drugs consumption and accelerometry wearing time entered as covariates. 


\section{DISCUSSION}

The current study shows that all PA levels (positively) and sedentary time (inversely) are correlated with different dimensions of HRQoL in women with fibromyalgia. Vigorous PA intensity level and sedentary time were independently associated with HRQoL dimensions (except for general health, emotional role and mental health). In concordance with the previous results, patients meeting the current PA recommendations showed better scores in bodily pain and social functioning dimensions of HRQoL compared to those not meeting the current PA recommendations. Our findings suggest that fibromyalgia patients should be encouraged in reducing sedentary time and increasing their levels of PA.

Diverse intervention studies have suggested that exercise is an effective alternative to improve symptomatology and HRQoL in patients with fibromyalgia (1418). However, as far as we know, only two previous studies have tested the link between the levels of PA and patients' perception of health status $(9,27)$. Sañudo et al. (9) found that patients who reported a moderate level of total PA presented a better physical function and general health. Culos et al. (27) also evidenced that the physical component of HRQoL was independently related with higher frequency of total PA. Overall, the results of these previous studies and ours concur when showing an association between PA and HRQoL. Nonetheless, several methodological issues make direct comparisons between our findings and those of prior investigations difficult. The sample size of previous studies was considerably lower than ours $(n=63$ (9) and 86 (27) vs. 407). Furthermore, they used questionnaires to asses PA levels, which have shown differences in the estimation of PA in this population when compared to an objective measure such as accelerometry (46). Additionally, categorization of PA levels between studies differed, 
with no inclusion of vigorous PA in any of the previous studies, intensity level in which we found the strongest associations with HRQoL.

Benefits of regular practice of PA for general health are well documented (29). However, the specific relationship between PA intensity levels and HRQoL in the general population remains controversial. While some studies suggest that increases in the intensity of PA is related to better HRQoL $(47,48)$, others authors have observed detriments in HRQoL in individuals exercising above recommendations (49). In the present study, patients who met the current PA recommendations presented significantly better scores in bodily pain and social functioning dimensions. In addition, vigorous PA was the only PA level independently associated with HRQoL, with patients reporting less limitations performing physical activities, less limitations due to pain and less interference with social activities due to health status (50). It is noteworthy that the association between physical function and PA could cause an overlap when self-reported tools are used, as suggested by Bize et al. (20). However, as we used an objective measure of PA, the actual association of PA intensity levels with the physical function of HRQoL is likely to be better described.

This study also fills a gap in the literature by evidencing an inverse relationship of objectively measured sedentary time with HRQoL independent of PA in women with fibromyalgia. The strongest association of sedentary time was observed with the social function dimension. The passive nature of different sedentary activities (watching television or seating on the computer) is thought to be accompanied with decreased communication and poor social network (51). On the contrary, participating in PA usually leads to increased social interactions, which is also in agreement with the positive correlations found between all the PA intensity levels and social functioning in the present study. As social isolation concerns are frequently report by these patients (4), moving to 
a more active lifestyle may positively influence this construct of health. Mechanisms that explains the deleterious relationship of sedentary behaviour and HRQoL have been less studied compared to those identified with PA. Nevertheless, some adaptations negatively related with the mental component of HRQoL such as stress, anxiety, depression or mental disorders have been connected to sustained sedentary behaviour (52). As pain intensity is an important explanatory variable of the impact of fibromyalgia on HRQoL (53), impaired pain regulation related to sedentary time (54) could additionally explain detriments in patients' reported health status. Prolonged sedentary behaviour compromise cardiometabolic health leading to increased cardiovascular risk, hypertension and diabetes (33). The fact that sedentary time is higher in fibromyalgia patients (30), added to the association found between sedentary time and HRQoL independent of PA in the current study, displays the importance of this behaviour as a target for health promotion efforts in this group of patients.

The relationship found in the present study between PA and HRQoL is complex and might be also explained through intermediate factors. Self-efficacy, the centre of social cognitive theory (55), is a consequence itself of PA but also a potential mediator between PA and HRQOL (56). In fibromyalgia, self-efficacy has been additionally associated with less pain (57) and it is considered a predictor of PA and long-term therapeutic success $(58,59)$. It seems also important to highlight the possible intermediate role of pain given the previous research suggesting that PA is positively associated with mechanisms of pain modulation in this group (54). Positive changes in others constructs related to mental health (anxiety, depression (60), fatigue, social support, mood (61) or affect (62)) have been suggested to mediate in the pathway between PA and HRQoL in previous population-based studies as well. More closely related to physical component, participation in PA tends to be associated with benefits such as reduction of 
cardiovascular risk factors (63), improved sleep quality (64), improved fitness level or reduced functional limitations (60). Although this indirect relationship has been theoretically grounded in previous research, specific studies of the intermediary role of aforementioned factors among fibromyalgia patients is yet to be elucidated.

\section{Limitations and strengths}

Our study has several limitations and strengths. Since our results are derived from a cross-sectional study, the associations found cannot be explained via a causal pathway: while PA might improve HRQoL, it is possible that individuals with impaired HRQoL are less likely to participate in PA behaviour. Additionally, due to large quantity of factors related to HRQoL (5), is difficult to ascertain the true association between PA intensity levels and sedentary time with HRQoL. Given that only women took part in this study, future studies should investigate whether these associations also occur in men. In spite of these limitations, this study has several strengths including the use of accelerometers, which allowed us to objectively quantify intensities of PA and sedentary time. Furthermore, we assessed a relatively large sample size of women with fibromyalgia representative from southern Spain (Andalusia) (36). It is also noteworthy that our analyses were adjusted for a reasonable number of confounding factors.

\section{Practical implications and future research}

An important goal of researchers and clinicians in chronic care involves improving the HRQoL of patients. This might be accomplished by understanding social, psychological and behavioural components that affect HRQoL. In this line, our results showed that greater PA levels and, even more importantly, avoidance of sedentary time is associated with better perceived health status in women with fibromyalgia. In future studies it will be important to investigate the potential mediator effects of other variables 
suggested to have a theoretically possible role in the pathway between PA and sedentary time and HRQoL. Improved knowledge about the implications of those factors associated with HRQoL may help in developing interventions to promote general health in this group of patients. Future intervention and longitudinal studies might help to better understand the true relationship between PA, sedentary time and HRQoL.

\section{CONCLUSIONS}

This study showed that greater objectively measured PA is associated with better HRQoL in women with fibromyalgia. Furthermore, patients who meet the PA recommendations present significantly better bodily pain and social functioning. However, only vigorous PA was independently associated with HRQoL, specifically with physical function, bodily pain and social functioning. Moreover, sedentary time is also independently and inversely associated with physical function, physical role, bodily pain, vitality, social functioning, physical component and mental component dimensions of HRQoL.

\section{Acknowledgements}

We would like to thank all the members involved in the fieldwork, especially members from CTS-545 research group. We also gratefully acknowledge all the study participants for their collaboration. This study was supported by the Spanish Ministry of

Science and Innovation (I+D+I DEP2010-15639; BES-2011-047133; BES-2014067612), and the Spanish Ministry of Education (AP-2010-0963).

\section{Competing interests}

None of the authors have any conflict of interests. 


\section{REFERENCES}

1. Wolfe F, Clauw DJ, Fitzcharles MA, Goldenberg DL, Katz RS, Mease P, et al. The American College of Rheumatology Preliminary Diagnostic Criteria for Fibromyalgia and Measurement of Symptom Severity. Arthritis Care \& Research. 2010;62(5):600-10.

2. Carbonell-Baeza A, Aparicio VA, Sjostrom M, Ruiz JR, Delgado-Fernandez M. Pain and Functional Capacity in Female Fibromyalgia Patients. Pain Medicine. 2011;12(11):1667-75.

3. White KP, Nielson WR, Harth M, Ostbye T, Speechley M. Chronic widespread musculoskeletal pain with or without fibromyalgia: Psychological distress in a representative community adult sample. J Rheumatol. 2002;29(3):588-94.

4. Verbunt JA, Pernot D, Smeets R. Disability and quality of life in patients with fibromyalgia. Health Qual Life Outcomes. 2008;6:8.

5. Testa MA, Simonson DC. Current concepts - Assessment of quality-of-life outcomes. N Engl J Med. 1996;334(13):835-40.

6. Chapa DW, Akintade B, Schron E, Friedmann E, Thomas SA. Is Health-Related Quality of Life a Predictor of Hospitalization or Mortality Among Women or Men With Atrial Fibrillation? J Cardiovasc Nurs. 2014;29(6):555-64.

7. Otero-Rodriguez A, Leon-Munoz LM, Balboa-Castillo T, Banegas JR, Rodriguez-Artalejo F, Guallar-Castillon P. Change in health-related quality of life as a predictor of mortality in the older adults. Quality of Life Research. 2010;19(1):15-23.

8. Mapes DL, Lopes AA, Satayathum S, McCullough KP, Goodkin DA, Locatelli F, et al. Health-related quality of life as a predictor of mortality and hospitalization: The Dialysis Outcomes and Practice Patterns Study (DOPPS). Kidney Int. 2003;64(1):339-49.

9. Culos-Reed SN, Brawley LR. Fibromyalgia, physical activity, and daily functioning: The importance of efficacy and health-related quality of life. Arthritis Care Res. 2000;13(6):343-51.

10. Rooks DS. Fibromyalgia treatment update. Curr Opin Rheumatol. 2007;19(2):111-7.

11. Grumbach K. Chronic illness, comorbidities, and the need for medical generalism. Annals of family medicine. 2003;1(1):4-7. 
12. Nuesch E, Hauser W, Bernardy K, Barth J, Juni P. Comparative efficacy of pharmacological and non-pharmacological interventions in fibromyalgia syndrome: network meta-analysis. Ann Rheum Dis. 2013;72(6):955-62.

13. Mannerkorpi K, Henriksson C. Non-pharmacological treatment of chronic widespread musculoskeletal pain. Best Practice \& Research in Clinical Rheumatology. 2007;21(3):513-34.

14. Garcia-Martinez AM, De Paz JA, Marquez S. Effects of an exercise programme on self-esteem, self-concept and quality of life in women with fibromyalgia: a randomized controlled trial. Rheumatology International. 2012;32(7):1869-76.

15. Latorre PA, Santos MA, Heredia-Jimenez JM, Delgado-Fernandez M, Soto VM, Manas A, et al. Effect of a 24-week physical training programme (in water and on land) on pain, functional capacity, body composition and quality of life in women with fibromyalgia. Clinical and Experimental Rheumatology. 2013;31(6):S72S80.

16. Busch AJ, Schachter CL, Overend TJ, Peloso PM, Barber KAR. Exercise for fibromyalgia: A systematic review. J Rheumatol. 2008;35(6):1130-44.

17. Gavi M, Vassalo DV, Amaral FT, Macedo DCF, Gava PL, Dantas EM, et al. Strengthening Exercises Improve Symptoms and Quality of Life but Do Not Change Autonomic Modulation in Fibromyalgia: A Randomized Clinical Trial. PLoS One. 2014;9(3):8.

18. Wanderley FAC, Silva G, Marques E, Oliveira J, Mota J, Carvalho J. Associations between objectively assessed physical activity levels and fitness and self-reported health-related quality of life in community-dwelling older adults. Quality of Life Research. 2011;20(9):1371-8.

19. Balboa-Castillo T, Leon-Munoz LM, Graciani A, Rodriguez-Artalejo F, GuallarCastillon P. Longitudinal association of physical activity and sedentary behavior during leisure time with health-related quality of life in community-dwelling older adults. Health Qual Life Outcomes. 2011;9:10.

20. Bize R, Johnson JA, Plotnikoff RC. Physical activity level and health-related quality of life in the general adult population: A systematic review. Prev Med. 2007;45(6):401-15.

21. Davies CA, Vandelanotte C, Duncan MJ, van Uffelen JGZ. Associations of physical activity and screen-time on health related quality of life in adults. Prev Med. 2012;55(1):46-9. 
22. Freelove-Charton J, Bowles HR, Hooker S. Health-related quality of life by level of physical activity in arthritic older adults with and without activity limitations. J Phys Act Health. 2007;4(4):481-94.

23. Luncheon C, Zack M. Health-Related Quality of Life and the Physical Activity Levels of Middle-Aged Women, California Health Interview Survey, 2005. Prev Chronic Dis. 2011;8(2):11.

24. Toscano JJD, de Oliveira ACC. Quality of Life in Elderly Subjects with Different Levels of Physical Activity. Rev Bras Med Esporte. 2009;15(3):169-73.

25. Heesch KC, van Uffelen JGZ, van Gellecum YR, Brown WJ. Dose-response relationships between physical activity, walking and health-related quality of life in mid-age and older women. J Epidemiol Community Health. 2012;66(8):670-7.

26. Marck CH, Hadgkiss EJ, Weiland TJ, Van der Meer DM, Pereira NG, Jelinek GA. Physical activity and associated levels of disability and quality of life in people with multiple sclerosis: a large international survey. BMC Neurol. 2014;14:11.

27. Sañudo JI, Corrales-Sánchez R, Sañudo B. Nivel de actividad física, calidad de vida y niveles de depresión en mujeres mayores con fibromialgia. Escritos de Psicología (Internet). 2013;6(2):53-60.

28. Nijs J, Roussel N, Van Oosterwijck J, De Kooning M, Ickmans K, Struyf F, et al. Fear of movement and avoidance behaviour toward physical activity in chronicfatigue syndrome and fibromyalgia: state of the art and implications for clinical practice. Clin Rheumatol. 2013;32(8):1121-9.

29. Physical Activity Guidelines Advisory Committee Report, 2008. Nutrition Reviews. 2009;67(2):114-20.

30. Segura-Jiménez V, Álvarez-Gallardo I.C., Estévez-López F., Soriano-Maldonado A., Delgado-Fernández M., Ortega FB., Aparicio V., Carbonell-Baeza A-, Mota J., Silva P., Ruiz J.R. Differences in sedentary time and physical activity between women with fibromyalgia and healthy controls: The al-Ándalus project. Arthritis and Rheumatoloy. 2015; 67(11):3047-57.

31. Owen N, Sparling PB, Healy GN, Dunstan DW, Matthews CE. Sedentary Behavior: Emerging Evidence for a New Health Risk. Mayo Clinic Proceedings. 2010;85(12):1138-41.

32. Thorp AA, Owen N, Neuhaus M, Dunstan DW. Sedentary Behaviors and Subsequent Health Outcomes in Adults A Systematic Review of Longitudinal Studies, 1996-2011. American Journal of Preventive Medicine. 2011;41(2):20715. 
33. Owen N, Healy GN, Matthews CE, Dunstan DW. Too Much Sitting: The Population Health Science of Sedentary Behavior. Exerc Sport Sci Rev. 2010;38(3):105-13.

34. Strassnig M, Brar JS, Ganguli R. Health-related quality of life, adiposity, and sedentary behavior in patients with early schizophrenia: preliminary study. Diabetes, metabolic syndrome and obesity : targets and therapy. 2012;5:389-94.

35. Ellingson LD, Kuffel AE, Cook DB. Active and Sedentary Behavior Patterns Predict Mental Health and Quality of Life in Healthy Women. Medicine and Science in Sports and Exercise. 2011;43(5):817-.

36. Segura-Jimenez V, Alvarez-Gallardo IC, Carbonell-Baeza A, Aparicio VA, Ortega FB, Casimiro AJ, et al. Fibromyalgia has a larger impact on physical health than on psychological health, yet both are markedly affected: The al-Andalus project. Semin Arthritis Rheum. 2015;44(5):563-70.

37. Wolfe F, Smythe HA, Yunus MB, Bennett RM, Bombardier C, Goldenberg DL, et al. The American-College-of-Reumatology 1990 Criteria for the classification of fibromyalgia - Report of the multicenter criteria committee. Arthritis and Rheumatism. 1990;33(2):160-72.

38. Rodriguez-Andreu J, Ibanez-Bosch R, Portero-Vazquez A, Masramon X, Rejas J, Galvez R. Cognitive impairment in patients with Fibromyalgia syndrome as assessed by the Mini-Mental State Examination. Bmc Musculoskeletal Disorders. 2009; 10 .

39. Bennett RM, Friend R, Jones KD, Ward R, Han BK, Ross RL. The Revised Fibromyalgia Impact Questionnaire (FIQR): validation and psychometric properties. Arthritis Research \& Therapy. 2009;11(4).

40. Alonso J, Prieto L, Anto JM. The Spanish version of the SF-36 health survey - A measure of clinical outcomes. Med Clin. 1995;104(20):771-6.

41. Sasaki JE, John D, Freedson PS. Validation and comparison of ActiGraph activity monitors. Journal of Science and Medicine in Sport. 2011;14(5):411-6.

42. Choi L, Ward SC, Schnelle JF, Buchowski MS. Assessment of Wear/Nonwear Time Classification Algorithms for Triaxial Accelerometer. Medicine and Science in Sports and Exercise. 2012;44(10):2009-16. 
43. Aguilar-Farias N, Brown WJ, Peeters GMEE. ActiGraph GT3X+cut-points for identifying sedentary behaviour in older adults in free-living environments. Journal of Science and Medicine in Sport. 2014;17(3):293-9.

44. Malavolti M, Mussi C, Poli M, Fantuzzi AL, Salvioli G, Battistini N, et al. Crosscalibration of eight-polar bioelectrical impedance analysis versus dual-energy Xray absorptiometry for the assessment of total and appendicular body composition in healthy subjects aged 21-82 years. Ann Hum Biol. 2003;30(4):380-91.

45. Segura-Jimenez V, Aparicio VA, Alvarez-Gallardo IC, Carbonell-Baeza A, Tornero-Quinones I, Delgado-Fernandez M. Does body composition differ between fibromyalgia patients and controls? The al-Andalus project. Clinical and Experimental Rheumatology. 2015;33(1):S25-S32.

46. Segura-Jimenez V, Munguia-Izquierdo D, Camiletti-Moiron D, Alvarez-Gallardo IC, Ortega FB, Ruiz JR, et al. Comparison of the International Physical Activity Questionnaire (IPAQ) with a multi-sensor armband accelerometer in women with fibromyalgia: the al-Andalus project. Clinical and Experimental Rheumatology. 2013;31(6):S94-S101.

47. Morimoto T, Oguma Y, Yamazaki S, Sokejima S, Nakayama T, Fukuhara S. Gender differences in effects of physical activity on quality of life and resource utilization. Quality of Life Research. 2006;15(3):537-46.

48. Martin CK, Church TS, Thompson AM, Earnest CP, Blair SN. Exercise Dose and Quality of Life A Randomized Controlled Trial. Arch Intern Med. 2009;169(3):269-78.

49. Brown DW, Brown DR, Heath GW, Balluz L, Giles WH, Ford ES, et al. Associations between physical activity dose and health-related quality of life. Medicine and Science in Sports and Exercise. 2004;36(5):890-6.

50. Ware JE. SF-36 health survey update. Spine. 2000;25(24):3130-9.

51. Kraut R, Patterson M, Lundmark V, Kiesler S, Mukopadhyay T, Scherlis W. Internet paradox - A social technology that reduces social involvement and psychological well-being? American Psychologist. 1998;53(9):1017-31.

52. Sanchez-Villegas A, Ara I, Guillen-Grima F, Bes-Rastrollo M, VaroCenarruzabeitia JJ, Martinez-Gonzalez MA. Physical activity, sedentary index, and mental disorders in the SUN Cohort Study. Medicine and Science in Sports and Exercise. 2008;40(5):827-34.

53. Campos RP, Vazquez MIR. Health-related quality of life in women with fibromyalgia: clinical and psychological factors associated. Clin Rheumatol. 2012;31(2):347-55. 
54. Ellingson LD, Shields MR, Stegner AJ, Cook DB. Physical Activity, Sustained Sedentary Behavior, and Pain Modulation in Women With Fibromyalgia. J Pain. 2012;13(2):195-206.

55. Bandura A. Self-efficacy: The exercise of control. New York: Feeman; 1997.

56. McAuley E, Doerksen SE, Morris KS, Motl RW, Hu L, Wojcicki TR, et al. Pathways from physical activity to quality of life in older women. Annals of Behavioral Medicine. 2008;36(1):13-20.

57. Buckelew SP, Murray SE, Hewett JE, Johnson J, Huyser B. Self-efficacy, pain, and physical activity among fibromyalgia subjects. Arthritis Care Res. 1995;8(1):43-50.

58. Culos-Reed SN, Brawley LR. Self-efficacy predicts physical activity in individuals with fibromyalgia. J Appl Biobehav Res. 2003;8(1):27-41.

59. Muller A, Muller K, Blumenstiel K, Bieber C, Eich W. The concept of selfefficacy as important predictor of long-term therapeutic success in patients with fibromyalgia. Aktuelle Rheumatol. 2004;29(2):101-8.

60. Blane D, Netuveli G, Montgomery SM. Quality of life, health and physiological status and change at older ages. Social Science \& Medicine. 2008;66(7):1579-87.

61. Motl RW, McAuley E, Snook EM, Gliottoni RC. Physical activity and quality of life in multiple sclerosis: Intermediary roles of disability, fatigue, mood, pain, selfefficacy and social support. Psychology Health \& Medicine. 2009;14(1):111-24.

62. Elavsky S, McAuley E, Motl RW, Konopack JF, Marquez DX, Hu L, et al. Physical activity enhances long-term quality of life in older adults: Efficacy, esteem, and affective influences. Annals of Behavioral Medicine. 2005;30(2):13845 .

63. Li J, Loerbroks A, Angerer P. Physical activity and risk of cardiovascular disease: what does the new epidemiological evidence show? Curr Opin Cardiol. 2013;28(5):575-83.

64. Campos RMD, Silva A, de Queiroz SS, Neto MM, Roizenblatt S, Tufik S, et al. Fibromyalgia: level of physical activity and quality of sleep. Motriz. 2011;17(3):468-76. 
D. Miguel Ángel Calleja Hernández Vicepresidente y Secretario del Comité Ético de Investigación Clínica del Hospital Virgen de las Nieves

\section{CERTIFICA}

Que este Comité ha evaluado la propuesta del Investigador Principal D. Manuel Delgado Fernández para que se realice el estudio titulado: "Proyecto de Evaluación y Promoción de Calidad de Vida para enfermos de Fibromialgia" y que considera que:

Se cumplen los requisitos necesarios de idoneidad del protocolo en relación con los objetivos del estudio y están justificados los riesgos y molestias previsibles para el sujeto.

La capacidad del investigador y los medios disponibles son apropiados para llevar a cabo el estudio.

Son adecuados tanto el procedimiento para obtener el consentimiento informado como la compensación prevista para los sujetos por daños que pudieran derivarse de su participación en el estudio.

Y que este Comité acepta que dicho estudio sea realizado por el Grupo Ergolab de la Universidad de Granada, por D. Manuel Delgado Fernández como investigador principal.

Lo que firmo en Granada a dieciséis de abril de dos mil ocho

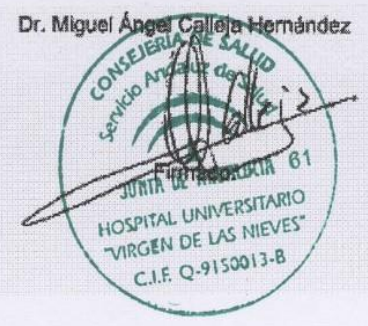

